\title{
PSYCHOEDUCATION FOR PSYCHOTIC PATIENTS
}

\author{
Jan Prasko ${ }^{\mathrm{a}, \mathrm{b}, \mathrm{c} *}$, Kristyna Vrbova ${ }^{\mathrm{a}}$, Klara Latalova ${ }^{\mathrm{a}}$, Barbora Mainerova ${ }^{\mathrm{a}}$ \\ a Department of Psychiatry, Faculty of Medicine and Dentistry, Palacky University Olomouc and University Hospital \\ Olomouc, Czech Republic \\ b Prague Psychiatric Centre, Ustavni 91, 18103 Praha \\ c Centre of Neuropsychiatric Studies, Ustavni 91, 18103 Praha \\ E-mail:prasko@fnol.cz
}

Received: June 16, 2010; Accepted: December 3, 2010; Available online: January 6, 2011

Key words: Group psychoeducation/Psychosis/Schizophrenia

Background. Psychoeducation programs have been shown in the last two decades to significantly improve the post-hospital discharge care of individuals with schizophrenia by demonstrated effects on rehospitalization rates, compliance with medication and knowledge. The benefits of psychoeducation can be sustained for up to seven years although most studies have not shown such enduring benefit. Psychoeducation is a type of psychotherapeutic support that aims to provide broad and adequate information on psychotic disorders for both patients and their families.

Method. The purpose of the group psychoeducational program at the Psychiatric clinic in Olomouc is to familiarize patients with the core of the disorder, explain the part played by pharmacotherapy, teach recognition of the warning signs of relapse, to advise on communication problems within families, and finally the training of social skills.

Results. Patients perceive the program as meaningful and helpful in better understanding their lives.

\section{INTRODUCTION}

Schizophrenia is a chronic psychiatric illness affecting $1 \%$ to $2 \%$ of the population. Unfortunately, suboptimal follow-through with treatment too often leads to a classic revolving-door pattern of relapse and rehospitalization. While the core intervention in schizophrenia remains antipsychotic medication; the limitations of medication alone in symptomatic, relapse prevention, and satisfaction/quality of life terms have long prompted interest in wider forms of management. This aside, in the CATIE study $^{1}$, a naturalistic randomized-controlled trial comparing five antipsychotic compounds, $74 \%$ of all patients discontinued their original medication before the end of the 18 months of the first phase of the trial.

One inherent deficit in schizophrenicia is an inability to engage appropriately in social and occupational activities. The debilitating effect of this is often a lasting feature of the illness, despite adequate psychopharmacological intervention, often isolating them and making it difficult for them to advocate appropriate social support or community services. Further, studies have found that there is a correlation between poor social functioning and relapse. One of the challenges of this area, is also wide interindividual variability although standardized measures have been developed to rate the social deficits. These assessments have become important tools in the determination of effective non-pharmacological treatment strategies. In addition to long-term pharmacotherapy, quality education is considered an additional important form of assistanc.

Family caregivers report high levels of burden related to caring for their mentally ill family members ${ }^{2}$. They may not have the knowledge and skills necessary to take on the caring responsibilities. As a result, patient relapse and readmission are common ${ }^{3}$.
Although no evidence of a definitive cause of schizophrenia is yet available, it can be reasonably controlled though the use of pharmacotherapy and psychosocial interventions. Relapse rates (measured by number of hospital readmissions or days in hospital) decrease significantly when schizophrenics adhere to specific pharmacological regimens and are exposed, together with their relatives, to psychoeducational programs $\mathrm{s}^{4}$. The level of partial or non-adherence in patients with schizophrenia is as high as $60 \%$, resulting in a higher risk of relapse, rehospitalization, suicidal attempts and is a major contribution to the economic burden of schizophrenia ${ }^{5,6}$. As insight into the illness was found to be among the strongest predictors for a positive adherence attitude, the need to enforce and incorporate adherence-focused psychotherapy and psychoeducation into daily clinical routine to improve adherence and therefore long-term outcome is highlighted.

A review of the literature shows that PEP (psychoeducational programs) have been conducted in a variety of ways. The duration of such programs has ranged from one to 18 months $^{7-11}$. They have consisted of 10 or more sessions, and the majority have been group interventions that included patients and their family members.

The various PEP models encompass individual consultation and family psychoeducation ${ }^{12,13}$, family therapy ${ }^{14}$, professionally led, short-term family education programs $^{15,16}$ and family-led support groups ${ }^{17}$. One program developed by the Psychoeducational Working Party of the Early Psychosis Prevention and Intervention Centre (EPPIC) focused on early intervention ${ }^{18}$. Despite different models and frameworks, these programs have a core content in common, such as explanation of schizophrenia (its nature and treatment), the management of problem behavior, accessing available resources, problem solving and coping skills. 
Existing studies have generally shown that PEP has positive outcomes. For example, PEP was effective in reducing relapse ${ }^{19,20}$ and improved patients' mental state, insight into their illness, and adherence to medication. Some studies, however, have suggested that it is unlikely that caregivers, particularly those of patients with a long history of illness, will change their views of patients after a short PEP intervention. Further, the difficulty in engaging patients and their carers during PEP has made the outcomes of the programs inconclusive $\mathrm{e}^{21-23}$.

In the United States, family psychoeducation interventions are currently considered one of five evidence-based psychosocial interventions for persons with severe mental illness, particularly those with schizophrenia ${ }^{24}$. As many as $65 \%$ of discharged psychiatric patients return to live with a family member ${ }^{25}$. Further, many families remain involved with their psychiatricall ill relative whether or not the relative lives with them ${ }^{26}$. Empirical studies suggest that curtailed activities, financial shortages, altered social relationships, high stress, marital strain, and burnout are among the problems faced by parents caring for a mentally ill child ${ }^{27}$. Concerns expressed by parents often include worry about their child's finances, feelings of helplessness, alarm over their child's dependency, confusion over how much assistance to offer, and wishing for their child to return to his or her "old self". There is increasing concern about what happens to the quality of life of people with psychiatric disability as their parents become unavailable to provide support and caregiving due to a lack of personal resources, disability, or death. A generation of parental caregivers for people with severe psychiatric disability will themselves become too old or disabled to be caretakers in the near future ${ }^{28}$. Without parental caregivers, the mentally ill who tended to rely on their parents may find themselves homeless, turning to additional family members for assistance, or needing more community services. Adult well siblings may be called upon to become caregivers for ill siblings when parents die or become disabled ${ }^{28,29}$. Numerous studies have reported adult siblings' concerns about the struggle of maintaining their own personal lives while simultaneously remaining involved with their ill family member ${ }^{30}$.

The main goal in working with families is to help them develop the knowledge and skills instrumental in promoting the recovery of their family member while eschewing family dysfunctional etiological theories of the past. Strong consensus about the critical elements of family intervention emerged in the late 1990s under the encouragement of the leaders of the World Schizophrenia Fellowship ${ }^{31}$. The resulting consensus on the elements for effective family intervention was as follows.

- Coordinate all elements of treatment and rehabilitation to ensure that everyone is working towards the same goals in a collaborative, supportive relationship.

- Pay attention to the social as well as the clinical needs of the patient.

- Provide optimum medication management.

- Listen to families and treat them as equal partners in treatment planning and delivery.
- Explore family members' expectations of the treatment program and for the patient.

- Assess the family's strengths and limitations in their ability to support the patient.

- Help resolve family conflict through sensitive response to emotional distress.

- Address feelings of loss.

- Provide relevant information for patient and family at appropriate times.

- Provide an explicit crisis plan and professional response.

- Help improve communication among family members.

- Provide training for the family in structured problemsolving techniques.

- Encourage the family to expand their social support networks, e.g., participation in multifamily groups or family support organizations such as the National Alliance on Mental Illness.

- Be flexible in meeting the needs of the family.

- Provide the family with easy access to a professional in case of need if the work with the family ceases.

The development of family psychoeducation interventions was based on earlier research that found that patients released from hospitals to families who expressed a high degree of hostility, criticism, and emotional overinvolvement were more likely to have an exacerbation of their symptoms and to relapse and be rehospitalized. Psychoeducational treatments, that have been developed and supported by over 25 years of research, that address the needs of family members have consistently shown that patients' outcomes improve when the needs of family members are met. Mental illness can affect family members across a range of domains, such as work, leisure, family health, children, and social relationships. Psychoeducation has been defined as systematic didacticpsychotherapeutic intervention, designed to inform patients and their relatives about the disorder and promote coping $^{32}$. In a 2003 survey of all psychiatric institutions in Germany, Austria and Switzerland, $86 \%$ of the responding institutions offered psychoeducation and in $84 \%$ of these for schizophrenia, mostly directed at patients during inpatient stay. Only $2 \%$ of family members however were involved $^{33}$.

A recent comprehensive meta-analysis ${ }^{34}$ identified seven randomized controlled trials utilizing inpatient or combined inpatient-outpatient family psychoeducation. Only four family psychoeducation programs in this review provided follow-up data on relapse or rehospitalization. Effect sizes ranged from 0.00 to 0.60 (mean 0.35 ) at one to six months and 0.12 to 0.69 (mean 0.55 ) at seven to 12 months post-intervention. The meta-analysis concluded that family psychoeducation showed benefit over patientonly psychoeducation and that gains were observed in relapse prevention but not in symptom reduction, functioning, knowledge, or adherence.

Psychoeducation can be targeted to the patient to improve outcomes, enhance compliance, and increase knowledge, including early relapse recognition, thereby contributing to a better sense of well-being. Imparting fac- 
Table 1. Content of psychoeducational program in Department of psychiatry University Hospit al Olomouc.

\begin{tabular}{|c|c|}
\hline $\begin{array}{l}\text { Session 1: } \\
\text { Where are borders between real and dreamy picture } \\
\text { of the world? What is psychosis? }\end{array}$ & $\begin{array}{l}\text { - Introduction of the group members, } \\
\text { - Explaining the purposes of the group } \\
\text { - Real and dreamy picture of the world } \\
\text { - What is psychosis? }\end{array}$ \\
\hline $\begin{array}{l}\text { Session 2: } \\
\text { What are the signs and symptoms of psychosis? }\end{array}$ & $\begin{array}{l}\text { - Types and prevalence of psychotic disorders } \\
\text { - Typical signs and symptoms of psychosis (positive, negative, } \\
\text { cognitive, affective and social) } \\
\text { - Circle vicious of hallucinations, delusions, abulia and social } \\
\text { isolation }\end{array}$ \\
\hline $\begin{array}{l}\text { Session } 3 \text { : } \\
\text { What cause psychosis? } \\
\text { What are the triggers and warning signs of relaps? }\end{array}$ & $\begin{array}{l}\text { - } \text { Causes of psychosis } \\
\text { - } \text { Biological causes } \\
\text { - Model vulnerability-stress } \\
\text { - Maintenance factors and triggers of relapses } \\
\text { - Early warning signs of relaps }\end{array}$ \\
\hline $\begin{array}{l}\text { Session 4: } \\
\text { How to treat psychosis pharmacologically? }\end{array}$ & $\begin{array}{l}\text { - Pros and cons of medication } \\
\text { - Mechanism of the effect of antipsychotics } \\
\text { - Practical aspects of using antipsychotics } \\
\text { - Effects and side effects of medication } \\
\text { - Myths about antipsychotics } \\
\text { - Psychosocial interventions }\end{array}$ \\
\hline $\begin{array}{l}\text { Session 5: } \\
\text { How to prevent relaps? }\end{array}$ & $\begin{array}{l}\text { - Self-help } \\
\text { - Life style } \\
\text { - How to manage stress } \\
\text { - Breath control and relaxation } \\
\text { - Managing voices } \\
\text { - Managing delusion experiences } \\
\text { - Time management and pleasure activities } \\
\text { - Physical health }\end{array}$ \\
\hline $\begin{array}{l}\text { Session } 6 \text { : } \\
\text { The role of family and communication }\end{array}$ & $\begin{array}{l}\text { - What can help family } \\
\text { - Positive aspects of interpersonal relationships } \\
\text { - Expressed emotions and family, over-protectiveness, over- } \\
\text { involvement, and criticism } \\
\text { - Social skills training (positive assertion, feedback, reaction to } \\
\text { critique } \\
\text { - Preparing for the future }\end{array}$ \\
\hline
\end{tabular}

tual materials is also a fundamental component of many educational interventions. These interventions were designed to reduce family environmental stress by educating families on the illness, ways to communicate more effectively with the patient, to improve problem solving skills, to cope better with the illness and hence to reduce re-hospitalizations.

Psychoeducation is a program of cognitive, behavioral, educational and supportive intervention within the complex program of treating psychotic patients. It is also psychotherapeutic with the aim of providing the necessary information about the psychotic disorder to the patient. The benefits of psychoeducation have the potential to be long lasting, up to seven years ${ }^{35}$, although most studies have not shown such enduring benefit ${ }^{34}$. The patient should learn that psychosis is a serious but treatable mental illness, whose essence is changed relationship to reality. It should allow him/her to gain greater insight into his/her morbidity. Ideally, if the patient can be led to note that the danger of the psychosis outbreak lies in the fact that the patient feels himself to be completely mentally healthy. Linszen et al. ${ }^{36}$ have suggested that single-family intervention usually provides individualized psychological support for family members in terms of: (i) information on the mental illness, (ii) patient management and coping with the illness and its symptoms, (iii) how to identify and solve the specific health problems and (iv) the needs of an individual family accurately. Studies have reported that contacts and interactions between group participants may affect their emotional support and practical help, which is extended to the post-intervention period ${ }^{37}$. Moreover, Maton $^{38}$ suggests the importance of understanding the helpful environment within an educational and supportive group for family members of a mentally ill patient.

Studies have indicated that there is a severe burden imposed upon the whole family when caring for a member with schizophrenia, because of unpredictable and bizarre behavior, external stressors of stigma and isolation, family 
conflict, emotional frustration and burnout ${ }^{39,40}$. FriedmanYakoobian et al. ${ }^{41}$ examined factors that may be targeted by psychoeducation programs in order to reduce distress and increase hope in family members of individuals with schizophrenia. Using separate stepwise multiple regressions, they examined the relationships among 51 family members' reactions to a loved one's illness (adaptive and maladaptive coping strategies, criticism, overinvolvement, and blaming attributions) and distress and hope. Maladaptive coping strategies significantly predicted more distress and less hope in participants. Further stepwise regressions examining the relationship between distress and hope and subgroups of maladaptive coping revealed that mental disengagement was a significant predictor of more distress and behavioral disengagement was a significant predictor of less hope. These results suggest that recovery-oriented psychoeducation programs that help family members remain engaged with their relatives and work through problems (rather than resorting to mental or behavioral avoidance) may be especially helpful for reducing distress and increasing hope in caregivers of the mentally ill.

Schizophrenic disorders are chronic disorders usually characterized by relapses alternating with periods of remission. A better understanding of the course of schizophrenic disorders is available with the models of psychotic vulnerability and the neurodevelopmental hypothesis. The relapses have a number of serious aspects. Relapse prevention also constitutes a major public health issue. This is made possible by identifying relapse prodromal signs (or early signs of relapse). The relapse prodromal signs are often nonspecific but remain stable for each patient. They are more similar to the initial prodromal signs, also in symptomatology than to their chronic form. Specific psychoeducation strategies allow for each patient to learn his/her own stressful events and own prodromal signs of relapse, as well as onset of each prodromal symptom ${ }^{42}$.

Chadzyńska et al. ${ }^{43}$ found that the schizophrenic patients want more information on the illness and more knowledge on how to cope with symptoms in order to improve the quality of their lives. It is important for therapists to create an empathetic atmosphere for mutual understanding. During the psychoeducation sessions the therapist should use various methods for ensuring patient participation.

\section{TYPES OF PSYCHOEDUCATION PROGRAMS}

Psychoeducation is an intervention, which is aimed mainly at providing patients and their relatives sufficiently comprehensive and relevant information about schizophrenia. An integral part of it, however, is behavioral techniques aimed to help with stress management, elimination of communication traps in the family leading to over-emotionalism (see above) and also training in early detection of signs of impending deterioration in mental state. This usually includes some social skills training for the patients and information about the disease and the management of expressed emotions for the relatives. As a result of the early age of onset, its relapsing nature, and persistence of many clinical features, schizophrenia can potently disrupt the smooth acquisition and evolution of skills essential for developing mature interpersonal relationships, occupational competence, and independent living. Social skills training is based on a structured learning-orientated approach to the acquisition of skills relevant to the individual and the demands of his/her environment.

In general, patients appreciate sessions in which their illness is explained, reinforcing the idea that some understanding is possible in situations which may seem incomprehensible. Furthermore, explaining bizarre experiences and beliefs in illness terms can help de-stigmatize preconceptions they themselves may hold.

Programs differ in organization and content (individual family psychoeducation, individual family psychoeducation with group psychoeducation for relatives, family psychoeducation groups ${ }^{44,45}$.

In the Czech Republic, in recent years a parallel group psychoeducation program for patients and their relatives called „PRELAPSE“ was initiated. This was developed at the Munich psychiatric clinic in a team led by Kissling ${ }^{46}$.

Originally created by Anderson et al. ${ }^{47}$, family psychoeducation (FPE) for schizophrenia involves intensive engagement efforts with family and patient followed by extended education about the disease and guidelines for recovery based on research and best clinical practice. It pursues a careful, gradual process to promote strong stable symptomatic recovery and relapse prevention, and it incorporates problem solving based on the needs and wants of both family and patient. FPE emphasizes partnering and joining with family members and incorporating family members' and patients' goals as the core of the treatment plan. FPE for schizophrenia was heavily influenced by findings that psychotic relapse is a major impediment to longer term clinical and functional improvement ${ }^{48}$. But after roughly a year of remission, most people with schizophrenia make significant functional gains, are more resistant to stress, and can tolerate increasing mental and physical demands. This translates into working closely with the family, making coordinated efforts toward improved community participation, and using clinical conditions as the guide to what a patient can handle. Finally, FPE uses clinical skills and expertise in training families to assist in creating an optimal psychosocial environment for recovery from schizophrenia. Optimal environments are those that are somewhat quieter, less intense, and less complex than the world in general. Family members are assumed to be functional until proven otherwise (for example, by resisting or failing to use the treatment). Family members are instructed on and encouraged to implement specific strategies to create a low stimulation social environment to adapt to, and compensate for, the specific sensory and cognitive characteristics of a given disorder.

The term multiple family group psychoeducation (MFG) refers to a specific FPE treatment that combines education about mental illness, family support, crisis intervention, effective communication strategies, and problem-solving training ${ }^{49}$. MFG attempts to reflect 
contemporary understanding of schizophrenia and other severe mental illnesses from biological, psychological, and social perspectives. MFG comprises three components that roughly correspond to the phases of the group. In the first phase, the therapist emphasizes joining with each family in a single-family format, conducting a multifamily educational workshop, focusing on preventing relapse and fostering social and vocational rehabilitation. Family members and consumers meet with two clinicians for 90 min on a regular basis (typically bi-weekly) and utilize a structured problem-solving format to guide the group process. The second phase involves moving beyond stability to gradual increase in patient community functioning. This usually occurs during the second year of the MFG. The third phase comprises deliberate efforts to mold the family into a social network that can persist for an extended period and satisfy family and patient needs for social contact, support and ongoing clinical monitoring. This format is also an efficient context in which to continue psychopharmacologic treatment and routine case management. Expansion of the families' social networks occurs through problem solving, direct emotional support and out-of-group socializing, all involving members of different families in the group.

MFG is based on research showing that families attempting to cope with mental illness experience stressors that frustrate and discourage them. These responses often take the form of intensely-expressed emotion, in which relatives are highly critical or over-involved, a factor empirically shown to be associated with relapse ${ }^{50}$. Multifamily groups address social isolation, stigmatization, and increased financial and psychological burden directly. They achieve these by increasing the size and richness of the social support network, connecting the family to other families like themselves, providing a forum for mutual aid, providing an opportunity to hear the experiences of others who have had similar experiences and have found workable solutions, and building hope through mutual example and experience. A key component of MFG involves teaching families to implement the MFG Family Guidelines, which were developed for families based on the biology of the illness, to help them reduce stress in the environment and generally cope with the challenges of schizophrenia in the most calm and effective manner possible. Many controlled studies have found MFGs to reduce relapse, increase problem-solving skills, improve quality of life, and reduce burden among family members ${ }^{44,51}$. Programs fail to reduce relapse rates if they present information without also providing family members with skills training, ongoing guidance regarding illness management, and emotional support ${ }^{52}$. Additionally, a meta-analysis of 16 studies found that family interventions of fewer than 10 sessions had no important effects on relatives' burden ${ }^{53}$. The behaviors and disruptions of schizophrenia, in particular, may require more than education to ameliorate family burden and enhance patient outcomes. A number of studies have shown markedly higher reductions in relapse and rehospitalization rates among adults with schizophrenia whose families received psychoeducation than among those who received standard individual services, with differences ranging from $20 \%$ to $50 \%$ over 2 years ${ }^{54}$. For programs of more than 3 months' duration, the reductions in relapse rates were at the higher end of this range. Overall, the relapse rate for patients provided FPE has hovered around $15 \%$ per year, compared with a consistent $30 \%$ to $40 \%$ for individual therapy and medication or medication alone ${ }^{55}$. In 11 of the most rigorously designed and conducted studies, with an average study duration of 19.7 months, the overall average for family intervention was about $27 \%$, and for the control groups it was $64 \%$, a reduction of about $58 \%$ of the standard or routine treatment rate. Many studies reported in the past few years have demonstrated significant effects on areas of functioning other than relapse rates ${ }^{53}$. These studies address a frequent criticism of the randomized clinical trials: that relapse is only one dimension of outcome. Many patients and their family members are more concerned about the functional aspects of the illness, especially housing, employment, social relationships, and dating and marriage than about remission, a more abstract goal. More recently, several investigators have shifted focus to targeting these more human aspects of illness and life.

Shorter treatment programs (usually 8 to 25 meetings) are currently being promoted, that combine psychoeducation, providing information about the disease in the broader context of family therapy. Family psychoeducation has been found to reduce relapse but penetration rates are low.

\section{RESULTS OF PSYCHOEDUCATIONAL PROGRAMS}

Over two decades and an enormous body of research have suggested that patients living with families characterized by high levels of expressed emotion were more vulnerable to relapse ${ }^{56}$.

Earlier studies have suggested that educational interventions influence knowledge and drug use errors. Similarly, patient education improves compliance. An extensive study underway in the U.S. Schizophrenia Patient Outcomes Research Team (PORT), which aimed to find an effective psychosocial intervention for schizophrenia, recommended the inclusion of family psychoeducation programs into the therapeutic regimes ${ }^{57}$.

Pitschel-Walz et al. ${ }^{58}$ summarized the results of 25 studies focusing on psychoeducation of the families of schizophrenic patients. The effect of family psychoeducation has led to a reduction in the frequency of relapses by $20 \%$ compared to control groups, if psychoeducation lasted longer than 3 months.

Family psychoeducation is a highly effective but underused, evidence-based practice in the treatment of schizophrenia and other serious mental illnesses. Family psychoeducation (FPE) interventions have been developed to support families coping with the multiple challenges of serious mental illness (SMI) of a family member. While various FPE models have been developed, all interventions share a number of core elements, including an empathic, nonblaming stance toward the family; a direc- 
tive educational focus; and an emphasis on improving family members' communication and problem-solving skills. In a large body of randomized trials, FPE programs lasting 9 months or more have demonstrated robust effects in reducing rates of relapse and hospitalization and have also improved social and vocational functioning ${ }^{59}$. A number of meta-analyses ${ }^{58,60}$ and literature reviews ${ }^{59-62}$ indicate that FPE is an evidence-based practice. Even more modest levels of family involvement in treatment have been associated with a number of beneficial outcomes, including increased treatment participation ${ }^{63}$; greater satisfaction with care ${ }^{64}$; and improved hope, knowledge, and patient empowerment ${ }^{65}$. The Patient Outcomes Research Team (PORT) ${ }^{66}$, as well as practice guidelines of the American Psychiatric Association ${ }^{67}$ and Department of Veterans Affairs healthcare system ${ }^{68}$, strongly recommend family involvement in treatment as a critical element of quality care for persons with schizophrenia and other serious mental illnesses. Despite this consensus that FPE is an evidence-based practice, quality-of-care studies indicate that such interventions are rarely found in routine service settings for persons with serious mental illness. For example, in a sample of 902 schizophrenics from the PORT study and a VA extension sample, less than 8 percent reported that their family attended any kind of educational or support program ${ }^{69}$. The literature shows that barriers to the dissemination of family services exist at multiple levels within the mental health service system ${ }^{70}$, including system-level factors (e.g., lack of reimbursement or administrative support) and provider barriers (e.g., limited clinician knowledge about the benefit of family involvement, limited clinician skills in working with families, clinician attitude that family involvement will not help). In addition, family members may hesitate to participate in such services or experience practical barriers that limit their ability to attend programs (e.g., transportation difficulties, lack of child care). Finally, consumers of mental health services may have concerns about their family participating in their mental health treatment. Notably, little empirical data exist on implementation barriers to family participation in treatment among consumers with SMI. Existing studies have focused on barriers to agency adoption of $\mathrm{FPE}^{71}$ and providers' perceived barriers to implementing such interventions ${ }^{72}$. One particularly important variable to consider may be the frequency of consumer-family contact, since this may be a primary determinant of how patients experience their family relationships and think about family involvement in their treatment. A number of studies have reported that most patients with SMI have regular contact with their family. The PORT survey of 718 schizophrenics found that 83 percent had family in their local area and 51 percent had personal contact with family at least weekly. Similarly, in a sample of 423 schizophrenics enrolled in a VA cooperative study ${ }^{73}, 31$ percent had daily contact with family while they were in outpatient care, 33 percent had weekly contact, and 36 percent had less than weekly contact. However, earlier studies did not examine the relationship between frequency of family contact, patients experience of family relationships, and their views about family par- ticipation in their treatment. Frequency of family contact may have important implications for efforts to involve family in treatment. Consumers with more frequent family contact may have family members who are more readily available and interested in meeting with clinicians or attending family programs. Indeed, a number of studies that established the evidence base for FPE only included participants with high levels of family contact. For example, in an initial major trial of FPE, Falloon et al. ${ }^{74}$ only included patients living (or in close daily contact) with a biological parent. Another key study, McFarlane et al. ${ }^{44}$ required that participants to be living with their family of origin or have at least 10 hours of contact a week with participating family members. Relatively little is known about how consumers with less frequent contact with family view family participation in their treatment. For example, they may view family participation in treatment as unnecessary. Alternatively, those in less frequent contact with family possibly still value family participation in care. This issue is particularly important to consider among consumers whose primary family relationships are with siblings and extended family, since level of contact is typically lower in these types of family relationships. Murray-Swank et al. ${ }^{61}$ examined views about family relationships and family participation in care among a sample of 69 patients with serious mental illness receiving treatment within the Department of Veterans Affairs healthcare system. They found that younger patients and those with higher levels of psychiatric symptoms were more likely to report family conflict and distress. Of participating patients, $67 \%$ wanted family participation in their psychiatric treatment and those with at least weekly contact with family were more likely to want family participation. Consumers endorsed a number of barriers to family participation in their mental health treatment, including their own concerns about privacy and burdening family and skepticism that family involvement would be helpful.

Lincoln et al. ${ }^{34}$ used meta-analysis to evaluate the short- and long-term efficacy of psychoeducation (PE) with and without inclusion of families with regard to relapse, symptom-reduction, knowledge, medication adherence, and functioning. Randomized controlled trials comparing PE to standard care or non-specific interventions were included. A literature search in the Cochrane Library, PsycINFO and Medline retrieved 199 studies for closer examination, of which 18 , reporting on 19 comparisons, met the inclusion criteria. These studies were coded for methodology, participants, interventions and validity. Effect sizes were integrated using the fixed effects model for homogeneous effects and the random effects model for heterogeneous effects. Independent of treatment modality, $\mathrm{PE}$ produced a medium effect at post-treatment for relapse and a small effect size for knowledge. PE had no effect on symptoms, functioning or medication adherence. Effect sizes for relapse and rehospitalization remained significant for 12 months after treatment but failed significance for longer follow-up periods. Interventions that included families were more effective in reducing symptoms by the end of treatment and preventing relapse at 7-12 month follow-up. Effects achieved for PE directed at patients 
alone were not significant. It is concluded that the additional effort of integrating families in PE is worthwhile, while patient-focused interventions alone need further improvement and research.

Chien and Wong ${ }^{75}$ tested the effectiveness of a family psychoeducation group program over a 12-month period for families of Chinese patients in Hong Kong. The psychoeducation program is a needs-based group intervention that addresses the perceptions, knowledge, and skills of families in caring for relatives with schizophrenia. The psychoeducation group program consisted of 18 sessions; each session met every other week and lasted about two hours. The treatment program consisted of four stages that were based on the work of ${ }^{49}$ : orientation and engagement (three sessions), educational workshop (six sessions), therapeutic family role and strength rebuilding (seven sessions), and termination (two sessions). Patients participated in the six sessions of educational workshop. A controlled trial was conducted with 84 family members. Patient and family variables were measured at recruitment and at one week and 12 months after completion of the intervention. Multivariate analyses of variance showed that participants in the psychoeducation group reported greater improvements in families' and patients' functioning, families' burden of care, and the number and length of patients' rehospitalizations over the 12-month follow up period, compared with the standard care group. These findings support the effectiveness of the family psychoeducation group program in improving the psychosocial health and functioning of Chinese patients with schizophrenia and their families.

Although family psychoeducation has been shown to be highly efficacious in the treatment of schizophrenia, the mechanisms underlying the treatment's success are poorly understood. The therapeutic alliance in behavioral family management (BFM) was examined to determine whether the alliance plays a role in the efficacy of this treatment $^{76}$. One early BFM session (mean session $=$ $6.5)$ involving 28 schizophrenia patients and their relatives who participated in the National Institute of Mental Health's Treatment Strategies in Schizophrenia study was coded using the System for Observing Family Therapy Alliances. The results indicated that when relatives developed a positive therapeutic alliance, patients were less likely to show prodromal signs of relapse and be rehospitalized over a 2-year follow-up period. When patients developed a positive alliance, relatives became less rejecting and were less likely to feel burdened over a 2-year period. The data suggest that the development of a positive therapeutic alliance within family psychoeducation may play an important role in preventing the escalation of psychotic symptoms and improving family relationships.

The more recent and updated guidelines on schizophrenia underline the extreme importance of the families involvement in treatment of young people in the initial phases of illness. "Families are the main support for many young patients. They could be the primary carers but they have also to face individual and social consequences following the onset course ${ }^{77}$. Where feasible, family members must be involved in the treatment”. Programma 2000
("Niguarda Ca' Granda" Hospital-Milan) and is mostly focused on psychoeducation and on Expressed Emotions aspects. Even the advances suggested by the international literature drove Programma 2000 to define both the steps of caregivers assessment and intervention. During the last ten years, Programma 2000 has followed 191 caregivers. The aims of this progammeo are to verify the outcome of the "pilot project", started in 2007, projected specifically to increase the normally used strategies to improve caregivers adherence and involvement in the therapeutic process. The individualized multi-componential intervention has been structured in 8 sessions over one years. Outcome measures used are the scores of the Camberwell Family Interview and from the Psychosis Knowledge Assessement Semistructured Interview (VCP). The subjects enrolled in the structured pilot project were 25 families, caregiver to young (18-30 yrs old) patients. Results shows change in the Expressed Emotion level: 13\% of families moved from High Expressed Emotion to Low Expressed Emotion. Furthermore data on the knowledge of illness knowledge level illustrate a reduction in the percentage, from $47 \%$ to $18 \%$, of carers who have just a very vague knowledge of illness, and an increase from $16 \%$ to $27 \%$ of carers who obtain a good level of specific knowledge. In conclusion we can sustain mental health expert with aim to treatment project program individualized and multi-componential tailored for young's caregiver at the onset phase of psychosis.

Psychoeducation programs have been demonstrated to reduce relapse and be cost-effective for schizophrenia in academic settings, although this has not been examined in private care inpatient settings. A total of 57 consecutive patients hospitalized for an exacerbation of schizophrenia symptoms were randomly assigned to receive treatment as usual or Schizophrenia Treatment and Education Programs (STEPS), an intensive inpatient-initiated psychoeducation program in a private-sector treatment setting $^{78}$. Schizophrenia Treatment and Education Programs (STEPS), an intensive family psychoeducation program specifically designed as an inpatient initiated intervention for schizophrenia in a private-sector practice, is unique in not being based on any other existing psychoeducation program. It extends the capabilities of established psychoeducation models that are limited only to outpatients to begin the intervention during acute inpatient care, when the severity of illness and treatment intensity are maximal and the potential for benefit is large. The STEPS program translates the efficacy of psychoeducation demonstrated in academic environments into effectiveness in private sector settings. At six months, 54\% of the original sample was reassessed. Rehospitalization over six months was significantly less frequent among STEPS participants than among usual care participants (20\% versus $56 \%, \mathrm{p}=.038$, Hedge's g effect size=.76). This controlled study demonstrated subsequent reduction of costly rehospitalization among patients randomly assigned to STEPS, although study attrition of $46 \%$ over six months may diminish the confidence in the findings.

Chan et al. ${ }^{79}$ (2009) evaluated the effectiveness of a psychoeducation program for Chinese patients with 
schizophrenia and their family caregivers. Seventy-three patients with a diagnosis of schizophrenia and their caregivers $(n=73)$ were recruited and randomized into a study $(n=36)$ and control group $(n=37)$. Ten psychoeducation sessions were provided to the study group. The outcomes were measured at baseline, immediately after (post-1), six months (post-2), and 12 months after the intervention (post-3). There were significant treatment effects across time for all patient outcomes: adherence to medication $(p<0.01)$, mental status $(p<0.01)$, and insight into illness $(p<0.01)$. However, no significant differences were found between groups on post-3 measures for all patient outcomes. For the caregivers, significant group differences were only detected in self-efficacy at the post- $1(p=0.007)$ and post- $2(p<0.001)$ measures, the level of satisfaction at the post- $1(p=0.033)$ and post- $2(p<0.021)$ measures, and the perception of family burden at the post- 2 measures $(p=0.043)$. A psychoeducation intervention had positive effects on Chinese patients and their caregivers. However, these effects might not be sustained 12 months after the intervention. To substantiate its effects, psychoeducation should be an ongoing intervention, with its outcomes constantly evaluated.

Multiple family group psychoeducation (MFG) has been shown to be an effective component of family psychoeducation (FPE) in reducing symptom relapses and rehospitalizations for individuals with schizophrenia ${ }^{80}$. It is especially effective when family members participate on a consistent basis, which allows them to increase their understanding of the biology of the disorder, learn ways to be supportive, reduce stress in the environment and in their own lives, and develop a broader social network. When used in conjunction with medication, MFG can help an individual with schizophrenia progress towards the rehabilitation phase of recovery.

Pitschel-Walz et al. ${ }^{81}$ (2009) examined whether borderline intellectual disability in patients with schizophrenia limits the benefit from psychoeducational groups. A manualized, interactive psychoeducational program of eight sessions (4 weeks) was initiated. Measures of knowledge, adherence and the concept of illness were completed before and after the groups. The short-term outcome of 22 participants with schizophrenia and borderline intellectual disability (IQ 70-85) was compared with the outcome of 75 participants with schizophrenia and IQ $>85$. Results showed that individuals with schizophrenia and borderline intellectual disability could be successfully integrated into general psychoeducational groups. The conclusion is that borderline intellectual disability should not be an exclusion criterion for participation in such groups.

Reichhart et al. ${ }^{82}$ (2010) re analysed data sets of one randomised-controlled (study 1) and one naturalistic psychoeducation study (study 2). Main outcome measures (knowledge about schizophrenia, drug attitude, confidence in medication) were assessed at baseline, post-intervention and 12 months after index discharge. The reanalysed samples consisted in total of 1002 patients and 176 caregivers. In study 2, baseline knowledge was significantly better in male patients and female caregivers. All participants improved significantly their knowledge.
The amount of knowledge gain did not differ between genders in either study or either group. Gender was not a major predictor of baseline knowledge or knowledge gain. Only in study 1 did gender significantly impact the knowledge gain from baseline to follow-up. Regarding improvement in drug attitude, females seemed to benefit significantly better from psychoeducation. In both studies, however, changes in drug attitudes/confidence in medication were best explained by lower corresponding baseline scores, not gender. Patients' gender did not influence the outcomes of their caregivers. These findings suggest that psychoeducational programs might be better adapted to males in order to improve their drug attitude. Concerning knowledge, gender-related changes do not seem to be necessary.

\section{THE PSYCHOEDUCATIONAL PROGRAM AT THE DEPARTMENT OF PSYCHIATRY OF THE UNIVERSITY HOSPITAL IN OLOMOUC}

Although psychoeducational programs for patients with schizophrenia can significantly reduce relapse rates, few patients are offered a psychoeducational program in routine clinical treatment. Implementation difficulties and lack of experience, training, and time are considered as the primary reasons for this situation. Therefore, we prepared an easy, structured, psychoeducational program for schizophrenia in routine clinical treatment. These psychoeducational interventions follow a cognitive-behavioral model. Program comprises 6 modules that cover introduction to the group psychoeducation, symptoms and causes of schizophrenia, effects and side effects of medication, warning signs, relapse prevention, self-help, and role of the family and communication.

The purpose of the psychoeducational program of the Psychiatric clinic in Olomouc is to familiarize patients with the essence of the disorder, the role and principles of pharmacotherapy, recognition of the warning signs of relapse, to advise on inappropriate and stressful stereotypes in communication within families and finally the training of social skills. The basic principles of psychoeducational interventions are simple, factual and adequate information about the disorder and its possible treatment methods ${ }^{83}$. The goal is also to try to make the patients aware of those problems that are related to the disorder, the communication difficulties and the most appropriate management of the stressors and life events. All of these elements allow the patients to become more conscious and more able to deal with problems, fostering therefore an easier and more effective course of the illness, especially when the psychoeducational interventions are associated with appropriate and long-term drug treatment ${ }^{84,85}$. Among factors influencing adherence, the clinician's style of communication and the therapeutic relationship are recognized as key. The content of our psychotherapeutic program, which currently runs in the Department of Psychiatry of the University Hospital, is as follows:

(1) Patients are provided information about the biological nature of schizophrenia, the symptoms of the disease, 
possible causes of schizophrenia, as well as about the consequences. Open discussion within the group helps patients eliminate of the feeling that the illness is only a portion of their individual lives.Similar experiences of other participants can be connected to a unifying framework for the consequences of a biological disorder of the brain. Part of psychoeducation can be information about the impact of alcohol and drug use on illness.

(2) In the course of therapeutic sessions patients also learn about psychopharmacology. Non-compliance in the treatment of psychosis is a common problem and has many causes. Patients often do not use medication due to distorted information on the adverse effects of drugs and also due to lack of information about the possible consequences of treatment interruptions.

(3) Another component of the educational program is training in recognition of the early warning signs. Timely interventions can both prevent hospitalization and emphasizes the new role of the patient as an active partner in the therapeutic alliance.

(4) There is high incidence of inappropriate communication stereotypes in the families, leading to increased expression of emotion (expressed emotion). Expressed emotion (EE) has been studied in families of a relative with schizophrenia as well as other psychiatric disorders; and high EE (hostile, critical, and over involved) families have been found to be strongly related to relapse ${ }^{24}$. When the families in this sudy were divided into two groups, families with high EE and those with low EE, it was found that discharged patients returning to a high EE family had a 3-4-fold higher risk of relapse than patients who returned to a low EE family ${ }^{86}$.

(5) The most important is an exaggerated, unconstructive criticism, which excessively interferes with the patient's privacy, increases the stress and may lead to the psychotic relapse or further increase in existing psychotic symptoms ${ }^{87}$. Relatives of the sick person are advised to not criticize the unusual behavior of the patient. The emphasis is on providing greater mental and physical space for the patient.

(6) A short social skills training is scheduled at the end of the course. The improvement of social skills is connected with decrease in the patient's life stress and also with decrease in psychotic symptoms and increase in life quality ${ }^{88}$. Basic social skills trained are:

- correct perception and understanding of information

- communication of positive information (compliments, awards)

- the initiation, continuation and closing short interview

- expression of negative emotions appropriately

- self-assertion (defending their own rights, reject unauthorized requests)

- ability to find a compromise
The contribution of psychoeducation programs are complex. They affect the course of disease by reducing the frequency of relapses, shortening the time of rehospitalization and improving the quality of life ${ }^{89}$. In addition the ratio of costs and benefits is favorable ${ }^{90}$.

\section{ACKNOWLEDGEMENTS}

Supported by the IGA MZ CR NS 10301-3/2009.

\section{REFERENCES}

1. Lieberman JA, Stroup TS, McEvoy J, Swartz MS, Rosenheck RA, Perkins DO, Keefe RS, Davis SM, Davis CE, Lebowitz BD, Severe J, Hsiao JK: Effectiveness of antipsychotic drugs in patients with chronic schizophrenia. N Engl J Med 2005;353(12):1209-1223.

2. Chan SW, Hsiung PC, Thompson D, Chen SC, Hwu HG. Healthrelated quality of life of Chinese people with schizophrenia in Hong Kong and Taipei: a crosssectional analysis. Research in Nursing \& Health 2007;30:216-69.

3. Chan SW, Yu IW. The quality of life of patients with schizophrenia. Journal of Advanced Nursing 2004;45:72-83.

4. Leff $\mathbf{J}$ and Waughn R: The role of maintenance therapy and relative expressed emotion in relapse of schizophrenia: a 2-year follow up. The British Journal of Psychiatry 1981;139:102-104.

5. Bartko G, Feher L. Pharmacoeconomic review of the use of injectable long-acting risperidone. Neuropsychopharmacologia Hungarica 2005;7(4):199-207.

6. Edwards NC, Locklear JC, Rupnow MF, Diamond RJ. Cost effectiveness of long-acting risperidone injection versus alternative antipsychotic agents in patients with schizophrenia in the USA. Pharmacoeconomics 2005;23(Suppl.1):75-89.

7. Atkinson JM, Coia DA, Gilmour WH, Harper JP. The impact of education groups for people with schizophrenia on social functioning and quality of life. British Journal of Psychiatry 1996;168:199-204.

8. Razali MS, Yahua H. Compliance with treatment in schizophrenia: a drug intervention program in a developing country. Acta Psychiatrica Scandinavica 1995;91:331-5.

9. Macpherson R, Jerrom B, Hughes A. A controlled study of education about drug treatment in schizophrenia. British Journal of Psychiatry 1996;168:709-17.

10. Hornung WP, Holle R, Schulze Monking H, Klingberg S, Buchkremer G. Psychoeducational-psychotherapeutic treatment of schizophrenic patients and their caregivers. II. Supplementary findings at a 2-year follow-up. Nervenarzt 1995;70:444-9.

11. Bauml J, Kissling W, Pitschel-Walz G. Psychoeducational groups among schizophrenicpatients: influence on knowledge and compliance. Result of the Munich PIP-study. Nervenheilkunde 1996;15:145-50.

12. Atkinson JM, Coia DA. Families coping with schizophrenia. A practitioner's guide to family groups. New York: John Wiley \& Sons; 1995.

13. Muser K, Sengupta A, Schooler N, Bellack A, Xie H, Glick I, Keith S. Family treatment and medication dosage reduction in schizophrenia: effects on patient social functioning, family attitudes, and burden. Journal of Consulting and Clinical Psychology 2001;69:3-12.

14. Marsh D. A family-focused approach to serious mental illness: empirically supported interventions. Sarasota: Professional Resource Press; 2001.

15. Mannion E. Training manual for the implementation of family education in the adultmental health systemof Berks County. PA: Philadelphia University; 2000.

16. Amenson C. Schizophrenia: a family education curriculum. Pasadena, CA: Pacific Clinics Institute; 1998.

17. Pickett-Schenk S, Cook J, Laris A. Journey of Hope program outcomes. Community Mental Journal 2000;36:413-24. 
18. Early Psychosis Prevention and Intervention Centre. Care management in early psychosis: a handbook. Melbourne: EPPIC; 2001.

19. Klingberg S, Buchkremer G, Holle R, Schulze Monking H, Hornung WP. Differential therapy effects of psychoeducational psychotherapy for schizophrenic patients-results of a 2-year followup. European Archives of Psychiatry and Clinical Neuroscience 1999;249:66-72.

20. Dixon LB, Adams C, Lucksted A. Update on family psychoeducation for schizophrenia. Schizophrenia Bulletin 2000;26:5-20.

21. Barrowclough C, Haddock G, Tarrier N, Lewis S, Moring J, O'Brien R, Schofield N, McGovern J. Randomized controlled trial of motivational interviewing, cognitive behavior therapy, and family intervention for patients with comorbid schizophrenia and substance use disorders. American Journal of Psychiatry 2001;158:1706-13.

22. McDonell MG, Short RA, Berry CM, Dyck DG. Burden in Schizophrenia caregivers: Impact of family psychoeducation and awareness of patient suicidality. Family Process 2003;42:91-103.

23. Kelly M, Newstead L. Family intervention in routine practice: it is possible. Journal of Psychiatric and Mental Health Nursing 2004; 11:67-71.

24. Solomon P, Alexander L, Uhl S: The relationship of case managers expressed emotion to patients‘ outcomes. Soc Psychiatry Psychiatr Epidemiol 2010 Feb;45(2):165-174. Epub 2009 Apr 16.

25. Goldman HH: Mental illness and family burden: A public health perspective. Hospital and Community Psychiatry 1982;33:557560 .

26. Carpentier N, Lesage A, Goulet I, Lalonde P \& Renaud M: Burden of care of families not living with young schizophrenic relative. Hospital and Community Psychiatry 1992;43:39-43.

27. Chafetz L \& Barnes L: Issues in psychiatric caregiving. Archives of Psychiatric Nursing 1989;3:61-68.

28. Lefley HP: Aging parents as caregivers of mentally ill adult children: An emerging social problem. Hospital and Community Psychiatry 1987;38:1063-1070.

29. Horwitz AV, Tessler RC, Fisher GA \& Gamache GM: The role of adult siblings in providing social support to the severely mentally ill. Journal of Marriage and the Family 1992;54:233-241.

30. Marsh DT \& Dickens RM: Troubled journey: Coming to terms with the mental illness of a sibling or parent. New York: Penguin Putnam Inc 1997.

31. World Schizophrenia Fellowship: Families as partners in care A document developed to launch a strategy for the implementation of programs of family education, training, and support. Toronto World Schizophrenia Fellowship 1998.

32. Wiedemann G, Klingberg S, Pitschel-Walz G, Psychoedukation A Psychoedukative Interventionen in der Behandlung von Patienten mit schizophrenen Störungen. Nervenarzt 2003;74,789-808.

33. Rummel-Kluge C, Pitschel-Walz G, Bäuml J, Kissling W: Psychoeducation in schizophrenia - results of a survey of all psychiatric institutions in Germany, Austria, and Switzerland. Schizophr Bull 2006;32,765-775.

34. Lincoln TM, Wilhelm K, Nestoriuc Y: Effectiveness of psychoeducation for relapse, symptoms, knowledge, adherence and functioning in psychotic disorders: A meta-analysis. Schizophrenia Research 2007;96:232-245

35. Bauml J, Pitschel-Walz G, Volz A, et al: Psychoeducation in schizophrenia: 7-year follow-up concerning rehospitalization and days in hospital in the Munich Psychosis Information Project Study. Journal of Clinical Psychiatry 2007;68:854-861.

36. Linszen D, Dingemans P, Van der Does JW, Nugter A, Scholte P, Lenoir R, Goldstein MJ. Treatment, expressed emotion, and relapse in recent onset schizophrenic disorders. Psychol Med 1996;26:333-42.

37. Citron M, Solomon P, Draine J. Self-help groups for families of persons with mental illness: perceived benefits of helpfulness. Commun Ment Health J 1999;35:15-30.

38. Maton KI. Moving beyond the individual level of analysis in mutual help group research: an ecological paradigm. J Appl Behav Sci 1993;29:272-86.

39. Asen E. Multiple-family therapy: an overview. J Fam Ther 2002;24:3-16
40. Solomon P, Draine J. Subjective burden among family members of mentally ill adults: relation to stress, coping, and adaptation. Am J Orthopsychiatry 1995;65:419-27.

41. Friedman-Yakoobian MS, de Mamani AW, Mueser KT: Predictors of distress and hope in relatives of individuals with schizophrenia. Isr J Psychiatry Relat Sci 2009;46(2):130-140.

42. Bottai T, Cotton I, Drigeard A, Vaglio V: [Prodromes of schizophrenia recurrence] [Article in French] Encephale 2009 Jan;35 Suppl 1:S33-40.

43. Chadzyńska M, Meder J, Charzyńska K: [The participation of patients with schizophrenia in psychoeducation-the analysis from the patients' perspective]. [Article in Polish] Psychiatr Pol 2009 Nov-Dec;43(6):693-703.

44. McFarlane WR, Lukens E, Link B, Dushay R, Deakins SA, Newmark M, Dunne EJ, Horen B, Toran J. Multiple family groups and psychoeducation in the treatment of schizophrenia. Arch Gen Psychiatry 1995;52(8):679-687.

45. McFarlane WR, Link B, Dushay R, Marchal J \& Crilly J: Psychoeducational multiple family groups: Four-year relapse outcome in schizophrenia. Family Process 1995;34(2):127-144.

46. Kissling W: Compliance, quality assurance and standards for relapse prevention in schizophrenia. Acta Psychiatr Scand Suppl 1994;382:16-24.

47. Anderson C, Hogarty G \& Reiss D: Family treatment of adult schizophrenic patients: A psychoeducational approach. Schizophrenia Bulletin 1980;6:490-505.

48. Hogarty GE \& Ulrich R: Temporal effects of drug and placebo in delaying relapse in schizophrenic outpatients. Archives of General Psychiatry 1977;34:297-301.

49. McFarlane WR: Multifamily Groups in the Treatment of Severe Psychiatric Disorders. New York, Guilford 2002.

50. Hooley JM, Rosen LR \& Richters JE: Expressed emotion: Toward clarification of a critical construct. In G.A. Miller (Ed.): The behavioral high-risk paradigm in psychopathology. New York: Springer Verlag 1995;88-120.

51. Weiden PJ, Scheifler PL, McEvoy JP, Frances A \& Ross R: Expert consensus treatment guidelines for schizophrenia: A guide for patients and families. Journal of Clinical Psychiatry 1999;(suppl 11): $1-8$.

52. Greenberg J, Greenley J \& Kim H: The provision of mental health services to families of persons with serious mental illness. Research in Community and Mental Health 1995;8:181-204.

53. Cuijpers P: The effects of family interventions on relatives' burden: A meta-analysis. Journal of Mental Health 1999;8:275-285.

54. Falloon IRH, Held T, Coverdale J, Roncone R \& Laidlaw T: Psychosocial interventions for schizophrenia: A review of longterm benefits of international studies. Psychiatric Rehabilitation Skills 1999;3:268-290.

55. Baucom DH, Shoham V, Mueser KT, Daiuto AD \& Stickle TR: Empirically supported couples and family interventions for marital distress and adult mental health problems. Journal of Consulting and Clinical Psychology 1998;66:53-88.

56. Bebbington P and Kuipers L: The prediction utility of expressed emotion in schizophrenia: An aggregate analysis. Psychological Medicine 1994;24,707-718.

57. Lehman AF, Steinwachs DM: Translating research into practice: The schizophrenia patient outcomes research team (PORT) treatment recommendations. Schizophrenia Bull 1998;24:1-10.

58. Pitschel-Walz G, Bauml J, Bender W, Engel RR, Wagner M, Kissling W. Psychoeducation and compliance in the treatment of schizophrenia: results of the Munich PIP-study. J Clin Psychiatry 2006;67(3):443-452.

59. McFarlane WR, Dixon L, Lukens E, Lucksted A. Family psychoeducation and schizophrenia: A review of the literature. J Marital Fam Ther 2003;29(2):223-245.

60. Pilling S, Bebbington P, Kuipers E, Garety P, Geddes J, Orbach G, Morgan C. Psychological treatments in schizophrenia: I. Metaanalysis of family intervention and cognitive behavior therapy. Psychol Med 2002a;32(5):763-782.

61. Murray-Swank A, Glynn S, Cohen AN, Sherman M, Medoff DP, Fang LJ, Drapalski A, Dixon LB: Family contact, experience of family relationships, and views about family involvement in 
treatment among VA consumers with serious mental illness. J Rehabilitation Research Development 2007;44(6):801-812.

62. Murray-Swank AB, Dixon L. Family psychoeducation as an evidence-based practice. CNS Spectr 2004;9(12):905-12.

63. Boyer CA, McAlpine DD, Pottick KJ, Olfson M. Identifying risk factors and key strategies in linkage to outpatient psychiatric care. Am J Psychiatry 2000;157(10):1592-98.

64. Prince JD. Family involvement and satisfaction with community mental health care of individuals with schizophrenia. Community Ment Health J 2005;41(4):419-430.

65. Resnick SG, Rosenheck RA, Lehman AF. An exploratory analysis of correlates of recovery. Psychiatr Serv 2004;55(5):540-47.

66. Lehman AF, Lieberman JA, Dixon LB, McGlashan TH, Miller AL, Perkins DO, Kreyenbuhl J, American Psychiatric Association, Steering Committee on Practice Guidelines. Practice guideline for the treatment of patients with schizophrenia, second edition. Am J Psychiatry 2004b;161(2 Suppl):1-56.

67. Lehman AF, Kreyenbuhl J, Buchanan RW, Dickerson FB, Dixon LB, Goldberg R, Green-Paden LD, Tenhula WN, Boerescu D, Tek C, Sandson N, Steinwachs DM. The Schizophrenia Patient Outcomes Research Team (PORT): Updated treatment recommendations 2003. Schizophr Bull 2004a;30(2):193-217.

68. Office of Quality and Performance Clinical Practice Guidelines [homepage on the Internet]. Washington (DC): Department of Veterans Affairs; c2005-7 [updated 2005 Feb 1]. Psychoses; [1 screen]. Available from: http://www.oqp.med.va.gov/cpg/PSY/ PSY_base.htm.

69. Resnick SG, Rosenheck RA, Dixon L, Lehman AF. Correlates of family contact with the mental health system: Allocation of a scarce resource. Ment Health Serv Res 2005;7(2):113-21.

70. Sherman MD, Carothers RA. Applying the readiness to change model to implementation of family intervention for serious mental illness. Community Ment Health J 2005;41(2):115-27.

71. McFarlane WR, McNary S, Dixon L, Hornby H, Cimett E. Predictors of dissemination of family psychoeducation in community mental health centers in Maine and Illinois. Psychiatr Serv 2001;52(7):935-42.

72. Dixon LB, Lyles A, Scott J, Lehman A, Postrado L, Goldman H, McGlynn E. Services to families of adults with schizophrenia From treatment recommendations to dissemination. Psychiatr Serv 1999;50(2):233-38.

73. Rosenheck RA, Cramer J, Jurgis G, Perlick D, Xu W, Thomas J, Henderson W, Charney D. Clinical and psychopharmacologic factors influencing family burden in refractory schizophrenia. The Department of Veterans Affairs Cooperative Study Group on Clozapine in Refractory Schizophrenia. J Clin Psychiatry 2000;61(9):671-676.

74. Falloon IRH, Boyd JL, McGill CW, Williamson M, Razani J, Moss HB, Gilderman AM, Simpson GM. Family management in the prevention of morbidity in schizophrenia. Clinical outcome of a twoyear longitudinal study. Arch Gen Psychiatry 1985;42(9):887-96.
75. Chien WT and Wong KF: A Family Psychoeducation Group Program for Chinese People With Schizophrenia in Hong Kong. Psychiatric Services 2007;58:1003-1006.

76. Smerud PE, Rosenfarb IS: The therapeutic alliance and family psychoeducation in the treatment of schizophrenia: an exploratory prospective change process study. J Consult Clin Psychol 2008;76(3):505-10.

77. Alpi A, Cocchi A, Meneghelli A, Pafumi N, Patelli G: [Working with families in the early stages of psychosis: a structured intervention for caregivers][Article in Italian]. G Ital Med Lav Ergon 2008 Jul-Sep;30(3 Suppl B):B62-70.

78. Vickar GM, North CS, Downs D, Marshall DL: A randomized controlled trial of a private-sector inpatient-initiated psychoeducation program for schizophrenia. Psychiatr Serv 2009;60(1):117-120.

79. Chan SW, Yip B, Tso S, Cheng BS, Tam W: Evaluation of a psychoeducation program for Chinese patients with schizophrenia and their family caregivers. Patient Educ Couns 2009;75(1):67-76.

80. Jewell TC, Downing D, McFarlane WR: Partnering with families: multiple family group psychoeducation for schizophrenia. J Clin Psychol 2009;65(8):868-878.

81. Pitschel-Walz G, Bäuml J, Froböse T, Gsottschneider A, Jahn T: Do individuals with schizophrenia and a borderline intellectual disability benefit from psychoeducational groups? J Intellect Disabil 2009;13(4):305-20.

82. Reichhart T, Pitschel-Walz G, Kissling W, Bäuml J, Schuster T, Rummel-Kluge C: Gender differences in patient and caregiver psychoeducation for schizophrenia. Eur Psychiatry 201;25(1):39-46. Epub 2009 Nov 18.

83. Buchkremer G, Klingberg S, Holle R, Schulze Mönking H: Psychoeducational psychotherapy for schizophrenic patients and their key relatives or care givers. Results of a 2-year follow-up. Acta Psychiatr Scand 1997,96:483-491.

84. Falloon IRH, Held T, Roncone R, Coverdale JH, Laidlaw TM: Optimal treatment strategies to enhance recovery from schizophrenia. Aust N Z J Psychiatry 1998,32(1):43-9.

85. Sherman MD, Fischer E, Bowling UB, Dixon L, Ridener L, Harrison D: A new engagement strategy in a VA-based family psychoeducation program. Psychiatr Serv 2009;60(2):254-257.

86. Brown GW, Birley JLT, Wing JK. Influence of family life on the course of schizophrenic disorders: A replication. Br J Psychiatry 1972;121:241-258.

87. Leff $\mathrm{J}$ and Waughn R: Expressed emotions in families. Guilford Press, New York, 1985.

88. Lieberman RP: Social skills training. In: Liberman RP (ed): Psychiatric rehabilitation of chronic mental patients. American Psychiatric Press, Washington DS;1987;147-198.

89. Motlová L, Španiel F, Vaňurová I. Psychoeducation and relapse of schizophrenia. European Psychiatry 2000;15(Suppl 2):349.

90. Dyck DG, Hendryx MS, Short RA: Service use among patients with schizophrenia in psychoeducational multiple-family group treatment. Psychiatric Services 2002;53:749-754. 
